\title{
The Generic Argument for teaching philosophy
}

\author{
Philip Cam \\ University of New South Wales \\ p.cam@unsw.edu.au
}

\begin{abstract}
John Dewey wished to place development of the ability to think at the core of school education. The kind of thinking that Dewey had in mind was based on his conception of scientific inquiry. Matthew Lipman was likewise committed to an education centred on thinking, but he claimed that we should turn to philosophy rather than to science in order to secure this end. In his view, philosophy has a stronger claim to this mantle than does science, or any other subject, when it is appropriately reconstructed and taught. He developed various arguments to that effect, but the one considered here is that philosophical thinking has a generic character that especially suits it for the role. I examine this argument to see how compelling a case it makes for the inclusion of philosophy in the school curriculum.
\end{abstract}

\section{Key words}

conceptual abilities; Dewey; higher-order thinking; inquiry; Lipman; reasoning

\section{Introduction}

John Dewey famously proclaimed that 'all which the school can or need do for pupils, so far as their minds are concerned ... is to develop their ability to think' (1966, p. 152). The most obvious contrast to be made with developing the ability to think is treating the mind as a storehouse to be filled with knowledge, as if the well-educated student were a talking encyclopaedia rather than a thinker. There are ways of unpacking the word 'think' that weaken this contrast, of course. We could treat the word 'think' as an umbrella term with which to provide shelter for the likes of 'remember', 'recall', 'recite' and 'affirm'. It is therefore important to note that Dewey's standard substitute for 'think' is 'inquire', a term that stands in opposition to memorisation, recitation and learning by rote. When he says that schools need to develop the ability to think, he is stressing the need for inquiry-based teaching and learning in schools. 
Dewey's claim is far more in tune with contemporary schooling than when Dewey made it a hundred years ago-in no small measure due to his influence. At least some recognition of the worth of an inquiry-based approach to school education can be found throughout the curriculum in many parts of the world. Its form may vary from one subject to another, owing to the differences between scientific inquiry, historical inquiry, moral inquiry, and so on. Yet commonality is also acknowledged in the stress that educators often place on thinking across the curriculum. The recent Australian Curriculum, for instance, treats critical and creative thinking as a general capability to which all subjects in the curriculum are to contribute. ${ }^{1}$ While inquiring is explicitly mentioned as only one of four elements of critical and creative thinking, recognisable inquiry procedures can be found in all of its elements and, as we will see later, the model as a whole can be rendered in those terms.

Since Dewey wanted inquiry to be embedded across the curriculum, it is of interest to ask from where he derives his conception of inquiry. As those familiar with Dewey's work will know, the kind of thinking he had in mind stemmed from his understanding of scientific inquiry. Dewey's monumental tome on this topic is his Logic: The Theory of Inquiry (1938), but there is a far less forbidding little book that he earlier wrote for teachers, entitled How We Think (1910). There Dewey draws examples from everyday inquiries to illustrate his general procedures, but he leaves us in no doubt that these procedures are garden variety versions of those to be found in science.

As something to be applied right across the curriculum, Dewey's conception is problematic. To take an obvious example, consider moral inquiry. Dewey long sought to overcome the dualism between what we call 'science' and 'morals' through 'a method of effective inquiry, which would apply without abrupt breach of continuity to the fields designated by these two words' (1998). The claim that moral problems and issues can be resolved by empirical methods is widely regarded as one of the least satisfactory features of Dewey's philosophy (for a brief summary of the criticisms levelled at Dewey in this regard, see Diggins 1994, pp. 243-249). This is not because facts are irrelevant, or because there is never a need to inquire into them. It is rather that the attempt to conduct ethical inquiry using empirical methods almost inevitably appeals to a situational and consequentialist metaethics that is in tension

\footnotetext{
${ }^{1}$ For an overview, see: https://www.australiancurriculum.edu.au/f-10-curriculum/generalcapabilities/critical-and-creative-thinking/. Given that the Journal of Philosophy in Schools is the official journal of the Federation of Australasian Philosophy in Schools Associations, I trust that my references to the Australian Curriculum will be particularly welcome to many readers. They are, however, used to illustrate general points.
} 
with other ways of arriving at ethical judgments and decisions. Those who appeal to religious moral principles, for example, or to principles derived purely from reason, are never going to agree that whether an action is right or wrong, say, is a purely empirical matter. In short, to say the least, it is philosophically controversial to claim that moral problems can be settled empirically. This applies not only to moral inquiry, but to any kind of values inquiry. In terms of standard school subjects, it obviously applies to such things as literary appreciation in English and aesthetic inquiry in Art. Nor does moral inquiry need to be confined to subjects specifically devoted to moral education. Going back to the Australian Curriculum, where ethical understanding is just like critical and creative thinking in being regarded as a general competence, it would become a concern across the curriculum, wherever ethical understanding is in focus and Deweyan inquiry methods were used.

Given the evident difficulty of superimposing a science-based model of inquiry over the entire curriculum, we need to ask whether there are any better candidates for that role. After all, it may be impossible to stretch any model of thinking across the curriculum without placing it on a procrustean bed. In that case, the call to place thinking at the heart of teaching and learning becomes an appeal to largely subjectspecific efforts, rather than the development of general thinking abilities. Since Dewey's day, the most obvious place to look for a contender is within the critical thinking movement, which has been devoted to the theory and practice of developing thinking skills, abilities and dispositions in education (for a representative sample of theories and approaches, Baron \& Sternberg 1987). The movement tends to treat thinking in a generic rather than a specific or disciplinary fashion. Among the programmatic approaches associated with this movement in its heyday is one of particular interest to us: Matthew Lipman's program of Philosophy for Children. While acknowledging his debt to Dewey, Lipman claimed that we should turn to philosophy rather than to science in order to promote thinking in education. He argued that philosophical thinking has the generic character that suits it for the role, enabling it to encourage thinking in, about, and among the subjects that students study at school. It is Lipman's argument from the generic character of philosophical thinking that I wish to consider.

Lipman's view was clearly that philosophy has a stronger claim to this mantle than science, or any other subject; and that the rich and diverse subject-matter of philosophy gives it advantages over purely process-driven approaches to the development of thinking. He made this claim in many places, but argued for it most 
extensively in Thinking in Education (1991). ${ }^{2}$ While the book never sets out the case all in one place, bringing his various remarks together makes for easier evaluation. This will be the task for the next section of this paper, following which I will examine the argument to see how compelling a case it makes for the inclusion of philosophy in the school curriculum.

\section{The Generic Argument}

Lipman begins Thinking in Education by declaring 'the capacity of philosophy, when properly reconstructed and properly taught, to bring about higher-order thinking in education to be significantly greater than the capacity of any alternative approach' Lipman 1991, p. 3). While he says that the book provides a 'prologue' in support of this claim, and so would ultimately need to be augmented, such a prolegomenon should make out at least a prima facie case for what is, after all, the book's main contention.

There are things in this contention that need to be unpacked before we begin to assemble the case that Lipman makes for it. First, what does he mean by higher-order thinking? Secondly, when Lipman says that philosophy needs to be properly reconstructed in order to realize its potential to promote higher-order thinking, what kind of reconstruction does he have in mind? Thirdly, how does Lipman think philosophy needs to be taught if it is to achieve that end? Let me address these preliminaries briefly.

Echoing Dewey's claim that the development of thinking should lie at the heart of school education, Lipman tells us that 'schools should primarily aim at the production of persons who can reason well, have good judgment, and are disposed to think in new ways' (1991, p. 92). Higher-order thinking, he maintains, is whatever kind of thinking is conducive to that goal. How, then, are we to recognise it? It will tend to be thinking, he says, that embraces complexity, strives for coherence, is answerable to evidence and logic, seeks meaning, and is energetic or intense, while generally being broad in its scope (Lipman 1991, p. 94). While this provides us with typical characteristics of the kind of thinking that Lipman believes will do the job, it would be better if he were to say something about that kind of thinking categorically and not just about its tendencies. Fortunately, this is just what he does at another point in the book. Higher-order thinking, he tells us, is equivalent to 'a fusion of

\footnotetext{
2 To my knowledge, there has been no extended discussion of Lipman's 'generic argument', which is surprising for such a well-known author. The lack of a critical literature to follow at least has the benefit of an opportunity to start one.
} 
critical and creative thinking' (Lipman 1991, p. 20). In joining this claim with the other remarks, we can say that, as Lipman conceives of it, higher-order thinking is a combination of critical and creative thinking marked by the tendencies listed above. This is the mode of thinking that needs to be developed if schools are to produce the kind of people that Lipman thinks they should turn out.

There is nothing exceptional about the suggestion that philosophy needs to be reconstructed for the purposes of school education. The same is true of other disciplines - such as physics, chemistry, history and mathematics - that have been converted into school subjects. If philosophy is going to make good on its promise of promoting higher-order thinking, however, Lipman believes that it needs to be reconstructed in a particular way. First and foremost, it needs to be done in a manner that provides students with the opportunity to engage in philosophical inquiry-not merely to become acquainted with the history of ideas, or the theories and arguments of contemporary philosophers. After all, philosophy cannot be expected to promote higher-order thinking unless students actually engage in philosophical thinking. Besides introducing students to an array of philosophical subject matter, attention therefore needs to be paid to the tools and procedures of philosophical inquiry. This includes, in particular, the tools and procedures of conceptual exploration and reasoning, such as making distinctions, defining terms, uncovering and applying conceptual criteria, constructing thought-experiments, searching for counterexamples and engaging in and evaluating both deductive and inductive inference and argumentation.

Lipman provided a model of such reconstruction by creating his own classroom materials, in which he abandoned the standard idea of a textbook in favour of philosophical novels set within the life-world of students. The novels revolve around philosophical problems and issues that are intended to stimulate students to raise their own questions as a basis for inquiry-based discussion. Lipman and his colleagues also constructed teachers' manuals to accompany the novels, providing teachers with a wide array of discussion plans, exercises and activities to help them conduct discussion and teach students the tools and procedures of philosophical inquiry.

Lipman's way of reconstructing philosophy for the classroom is of a piece with the way that he thought philosophy should be taught. He wanted to have students engage in what he called a Community of Inquiry. That notion has its roots in Charles Sanders Peirce's conception of the scientific community, as well as in John Dewey's joint concern with thinking in education and education for democracy - 
democracy being for Dewey an open and inquiring form of community life (Peirce 1955, pp. 5-22; Dewey 1966, chapters 7 \& 12). Lipman fashioned the cognitive and social dimensions of these ideas into the distinctive educational form of the discursive, inquiring classroom community. He took it be the ideal arrangement for teachers to establish collaborative thinking practices, which students would gradually internalise. While this was Lipman's preferred setting for classrooms in general, his application of it to the philosophy class was meant to have a special role in the development of higher-order thinking.

To insist that the philosophy class should take the form of a Community of Inquiry, gives us one more thing to sort out before we attempt to reassemble Lipman's argument. We have moved from talking about critical and creative thinking to talking about inquiry. That move needs to be justified. Dewey couched thinking in terms of inquiry, of course, and in Lipman's writings critical and creative thinking and inquiry are joined at the hip; but at this point we had best start with a characterisation of critical and creative thinking that is not already committed to an inquiry-based conception. The treatment of critical and creative thinking in the Australian Curriculum makes a handy reference point. ${ }^{3}$ It is a general competence model, but mentions inquiry as only one of its elements. The model has four organising elements presented in the following order:

- inquiring by identifying, exploring and clarifying information

- generating innovative ideas and possibilities

- analysing, synthesising and evaluating of information

- reflecting on thinking, actions and processes

\footnotetext{
${ }^{3}$ It was developed by the Australian Curriculum, Assessment and Reporting Authority (ACARA).

For the diagram below and an overview, see

http://www.australiancurriculum.edu.au/generalcapabilities/critical-and-creative-

thinking/introduction/key-ideas
} 


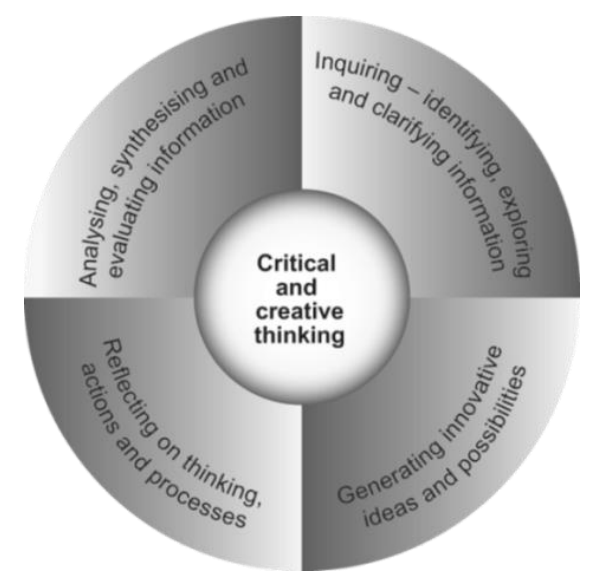

The ACARA Model of Critical and Creative Thinking

Although 'inquiring' is explicitly identified as only one of the elements in the ACARA model, very little analysis is required to show that all of the elements can be recast in that form. This is because inquiry involves identifying, clarifying and exploring questions, issues and problems in ways that accommodate the other three elements. First, inquiry involves a search for solutions, resolutions or answers that proceeds in the face of competing ideas and possibilities. So it generates possible responses and innovative ideas-suggestions, proposals, hypotheses, and the likesuch as we find in the 'generating' sector of the ACARA model. Secondly, in an inquiry these ideas and possibilities are only tentative solutions, thoughts about how things might be decided, or possible answers to questions, until they are properly examined and assessed; and putting such ideas and other suggestions to the test means analysing them, connecting and combining them, as well as evaluating them, as in the 'analysing/synthesising/evaluating' element. Finally, any well-developed inquiry will have a meta-cognitive dimension in that inquirers keep one eye on the inquiry process, consciously and deliberately implementing procedures and reaching for tools that will carry the inquiry forward in a structured and systematic way, in accord with the 'reflecting' element in ACARA's model. ${ }^{4}$ In all, then, inquiry mirrors all four elements of the ACARA model of critical and creative thinking.

\footnotetext{
${ }^{4}$ Keeping one eye on content and the other eye on process is what Lipman calls 'complex thinking'. While he regards it as a third component of excellence in thinking, alongside critical and creative thinking, it also has a critical thinking role in the management of inquiry. See Lipman (1991, pp. 2325).
} 


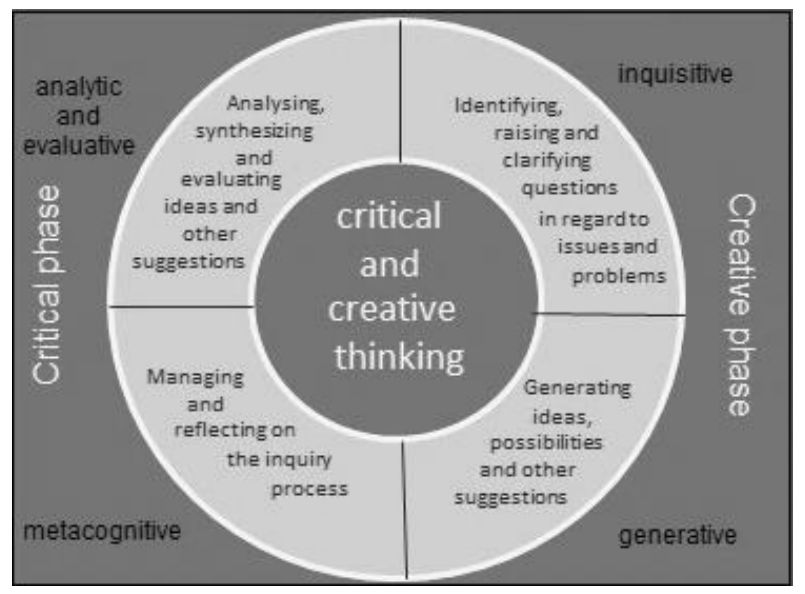

\section{An Inquiry Model of Critical and Creative Thinking}

Broadly speaking, what I am calling the inquisitive and generative elements of inquiry are the more creative ones, while the analytic/syntheticlevaluative and metacognitive elements are more critical. Looked at as a process, inquiry has creative and critical phases. As Lipman points out, however, we are unlikely to find critical thinking without at least a modicum of creative thinking, and vice versa (Lipman 1991, p. 21).

That inquiry incorporates all of the elements of an independently conceived account of critical and creative thinking shows that inquiry is a way of engaging in critical and creative thinking, but not necessarily that it is an educationally preferable way of doing so. Still, the mere fact that all of the elements can be addressed by engaging students in inquiry-based work makes it an attractive option. Such an approach also avoids the pitfall of a taxonomic treatment of the elements, as if critical and creative thinking could be taught through independent exercises for each of them.

This brings us at last to the case that Lipman makes for claiming that philosophy has a special role to play in developing higher-order thinking. He says that, while higher-order thinking needs to be cultivated in each discipline, there is considerable but varied overlap in their methodologies. Reasoning about propositions is a pervasive practice, for instance, while scientific method has widespread but far from universal application, which involves but does not exhaust the use of mathematical methods. Lipman maintains that, in this respect, philosophy has a unique relationship to the other disciplines, in that it alone employs truly generic thinking skills. We have already seen that Deweyan science-based thinking is too narrow to be applied across the board. The other candidate commonly considered to generally encourage thinking is studies in language and literature; but Lipman says that such 
studies are 'too diffuse and diversified' for general instruction in thinking (Lipman 1991, p. 179). Literary studies may improve the reading and writing skills associated with literacy, but philosophy is much better placed to develop general-purpose reasoning and conceptual skills, as well as the skills that underpin judgment (Lipman 1991, p. 179). 'Philosophy is to the teaching of thinking, 'says Lipman, 'what literature is to the teaching of reading and writing' (1991, p. 30). Were we as serious about students' reasoning and conceptual capabilities as we are about these basic aspects of literacy, we would ensure that philosophy was an essential part of the curriculum.

Lipman points out that philosophy not only employs general-purpose thinking skills, it also involves a great deal of thinking about its thinking. It is a highly metacognitive discipline, exemplifying this aspect of critical thinking to a high degree. This is evidenced in the careful attention given to the construction and evaluation of argument, for example, and the detailed analysis of the concepts used. This combination of generic thinking skills and cognitive surveillance of the proceedings means that philosophy can be used to make students ready to think and reflect in the other disciplines: 'Philosophy encourages thinking in the disciplines because it assumes the burden of teaching the generic aspects of thinking that goes on in any discipline and because it is a model of what it means for a discipline to reflect on and be critical of its own methodology' (Lipman 1991). ${ }^{5}$

Whether or not philosophy is unique in this way, Lipman is right to point out that 'it is difficult to conceive of overcoming uncritical thinking without recourse to at least a moderate amount of logic 'and that 'insofar as philosophy is the discipline that is ... concerned with the establishment of criteria, it is difficult to see how we could responsibly engage in critical thinking without to some extent internalizing this aspect of philosophical practice' (Lipman 1991, p. 178). So let us look a little more closely at the contribution that philosophy may make to the development of students' powers of reasoning.

Although schools go to great lengths to develop competence in mathematical reasoning, the same cannot be said of reasoning in its discursive form. Literature and

\footnotetext{
${ }^{5}$ In order to concentrate on the key claim of what I am calling the 'Generic Argument' I will set aside the two companion claims that Lipman makes on the same page regarding philosophy's capacity to encourage thinking in relation to other studies, namely: 'Philosophy encourages thinking about the disciplines, inasmuch as one of its prime modes of operation is the "philosophy of" course: philosophy of mathematics, philosophy of the social sciences, philosophy of language, and so on,' and it 'encourages thinking among the disciplines in order to forestall the provincialism that often accompanied professional specialization.' These claims can be interpreted as extensions of the generic argument, but I will not argue for that here.
} 
language studies cannot be compared to mathematical ones in this respect. Teachers of English language and literature, for example, are likely to pay particular attention to such things as spelling, vocabulary, grammar and aspects of style, but attend to reasoning only incidentally. This may be due to their lack of formal logical training, but it is also likely to be a consequence of the common presumption that reasoning competence comes along with language acquisition and requires no specialised attention. As Lipman notes:

Teachers are seldom educated so as to be on the lookout for logical floundering among their pupils or knowledgeable enough to correct such errors with confidence. It is taken for granted that primary reasoning skills are acquired along with language-in itself, not an unreasonable presupposition. But it is also taken for granted that no provision need be made in the schools for diagnosing reasoning deficiencies or for correcting them in the way that schools employ specialists in the diagnosis and correction of reading deficiencies. (Lipman 1991, p. 31)

The presumption that logic automatically comes along with language also turns up in reading comprehension tests. As Lipman points out, performance in such tests relies on logical abilities, such as inferring what a passage implies and grasping the assumptions on which it is based, as well as detecting similarities and differences of meaning between passages or expressions through comparisons involving analogical reasoning (Lipman 1991, p. 38). Attention to these logical abilities would improve reading comprehension, but tend not to be emphasised by teachers.

By contrast, philosophy treats reasoning as something to be explicitly and systematically taught. Along with being able to draw appropriate inferences and construct well-formed arguments, this includes the ability to recognise, correct and avoid invalid and fallacious reasoning. The philosophy teacher is someone who specialises in helping students to diagnose and correct such deficiencies. To bring philosophy in from the margins of school education, therefore, would enable our schools to develop 'sensitivity to the logical aspects of discourse that has not been cultivated in our present-day system of education' (Lipman 1991, p. 27).

There is no question that these logical competencies are generic. They enter into such things as reading comprehension and written expression in ways that are integral to most school subjects. For all the differences between reading and writing in different subject areas, student performance in these tasks depends on general logical competencies and deficiencies. This is all the more reason to do something about the 
inadequate attention to reasoning in the standard school curriculum. It is a deficiency that philosophy - and perhaps only philosophy - can remedy.

Just as cognitive acts such as inferring, generalising, deducing and concluding fall under the general heading of reasoning, so acts such as clarifying, distinguishing, classifying and defining fall under conceptualisation. Lipman maintains that here too there are generic aspects of higher-order thinking that philosophy is in a privileged position to supply.

In order to consider the contribution that philosophy may make to the development of students' capacities to think conceptually, we need to disentangle two claims that Lipman sometimes runs together. One is that 'philosophy is a miscible subject that permeates the other disciplines', each of which face their own epistemological, metaphysical, ethical and logical problems and issues (Lipman 1991, pp. 141-142). To claim that other disciplines contain philosophically substantive issues in their mix is to say that their subject matter is partly philosophical. On this view, the sciences and other disciplines not only grew out of philosophy, but still carry a philosophical burden-regardless of whether that is recognised and addressed. Yet, to say that these aspects of subject matter are philosophical is also to imply that the disciplines in which they arise cannot adequately deal with them using their own tools and procedures. In order to address them, they need philosophy as method. It is through the adoption and application of philosophical methods that philosophy can enrich the other disciplines and foster complex thinking in them. Philosophy's contribution, in short, is not so much a matter of content as it is of method.

Let us now apply this distinction between content and method to the claim that philosophy has a special role to play in encouraging conceptual thinking across the curriculum. ${ }^{6}$ Here is a relevant passage from Lipman:

Philosophy contains, along with many other things, a core of concepts. These concepts are embodied or illustrated in all the humanities, but it is in philosophy that they are analysed, discussed, interpreted, and clarified. (Lipman 1991, p. 163)

These concepts presumably include those that are notably epistemological, such as knowledge, fact, and understanding; those that are metaphysical, as in substance, property and cause; and those that are ethical, as with goodness, virtue and justice.

\footnotetext{
${ }^{6}$ There are different ways of thinking about the relationship between philosophy's subject matter and its methods. As suggested by the remarks above, one way of identifying subject matter as philosophical is to say that it is whatever subject matter is susceptible to philosophical methods. This is to define philosophy in terms of its methods.
} 
Many of them are not restricted to the humanities, of course, but may apply to all areas of the curriculum or have their primary applications elsewhere. While they have philosophical overtones, none of these concepts is unique to philosophy. It is its treatment of them-through analysis, distinction-making, disambiguation, clarification, classifying and defining, and uncovering and deliberating about conceptual criteria - that makes philosophy's contribution distinctive.

Even if Lipman is overstating the case by implying that conceptual analysis, discussion, interpretation and clarification do not occur in other disciplines, it is certainly true that philosophy has honed these things to a fine art. No other discipline has consciously and deliberately developed precision tools for thinking conceptually to anything approaching the same extent. Although they come from philosophy, they are general purpose tools that can help us to think conceptually in any area of the curriculum. They are in that sense generic, just like the tools and procedures of reasoning that also have their origin in philosophy. The fact that they come from philosophy constitutes the core of Lipman's Generic Argument for its inclusion in the curriculum.

\section{Three lines of objection}

How strong a case does the Generic Argument provide for assigning philosophy this special place in the curriculum? We can begin to assess the argument by considering three obvious lines of objection to it. First, there are those who claim that thinking in education is discipline-specific; so that it can be fostered only within the context of a specific discipline and cannot be taught per se. From this it follows that philosophical thinking has its own disciplinary character and it is erroneous to present it as a generic form of thinking that can be applied across the curriculum. Secondly, there are those who argue for the inclusion of general thinking skills programs in education that are not avowedly philosophical. The presumption here is that there are general-purpose thinking skills, but they are not the monopoly of philosophy. Consequently, showing that philosophy embodies such skills provides no special warrant for its inclusion in the curriculum. Thirdly, even granting that there are generic thinking skills and that philosophy is pre-eminent in that regard, the Generic Argument may be all well and good in theory, but it is ultimately an empirical matter whether philosophy can effectively supply them in school education. The movement inspired by Lipman has been active in schools for many years, through which philosophy has been reconstructed and taught in the way that he proposed. 
So where is the evidence that it actually produces a significant increase in higherorder thinking? Let us consider these three lines of objection.

The first objection to the Generic Argument is based on the claim that thinking in education is always thinking about something within the context of a discipline and the thinking involved is specific to that discipline. So there are no generic thinking skills to teach. John McPeck ran this argument against leading members of the critical thinking movement who wanted to include special programs in school education devoted to critical thinking (McPeck 1981). Since Lipman responds to McPeck, let us look at McPeck's formulation of it. According to McPeck, the conceptual truth that thinking is always thinking about some particular thing $X$ implies that "the claim "I teach my students to think" is at worst false and at best misleading.'

In isolation from a particular subject, the phrase 'critical thinking' neither refers to nor denotes any particular skill. It follows from this that it makes no sense to talk about critical thinking as a distinct subject and that it therefore cannot profitably be taught as such. To the extent that critical thinking is not about a specific subject $X$, it is both conceptually and practically empty. The statement 'I teach critical thinking' simpliciter, is vacuous because there is no generalized skill properly called critical thinking. (McPeck 1981, p. 5)

McPeck is obviously correct in claiming that there is no such thing as critical thinking except in relation to thinking about something in particular. You cannot think critically (or otherwise) without thinking about something, which will have its own particular content. Obviously too, the content with which we are concerned will normally be within a particular school subject. It does not follow from this, however, that the way the content is being thought about must also be subject-specific. That may be so, but the content might be subjected to operations of a general kind that apply across the curriculum. Valid deductive inference, for instance, applies independently of the particulars of subject matter, because the validity of the inference depends upon the form of the argument and not its particular content. To take an elementary example, any argument of the form

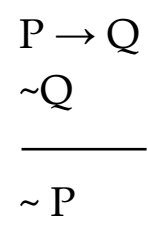

is deductively valid, irrespective of what we substitute for $\mathrm{P}$ and $\mathrm{Q}$. This is a general feature of logical operations and the same is true of conceptual operations. To take a 
classical example, consider Aristotelian definition in terms of genus and differentia. A cavalcade is a procession (genus) on horseback (differentia), just as a number $n$ is even if it is an integer (genus) and there is an integer $k$ such that $n=2 k$ (differentia). It makes no difference whether the particular matters we are thinking about are social, mathematical, or what have you. Definition in terms of these basic operations of classification and division has its limitations, but it is not subject-specific.

The means of constructing adequate definitions (or more broadly, of clear conceptualisation) is like devising logical procedures to ensure validity of argument (or more generally, to secure justifiable inference) in being traditional philosophical concerns with the quality of thinking. They serve to corroborate Lipman's claim that, in denying that there is any such thing as general critical thinking, McPeck 'ignores the flagrant counterinstance of philosophy'. As Lipman goes on to say:

The fact that logic and philosophy do exist, together with the fact that these are normative disciplines concerned with specifying what excellence in thinking ought to be-these facts are by themselves a refutation of McPeck's rejection of the notion that there is a discipline specifically devoted to the teaching of thinking as an autonomous activity. (Lipman 1991, p. 112)

The fact that philosophy has an ample supply of general-purpose thinking tools does not mean that they cannot be procured elsewhere, of course. It may be, for example, that we can greatly improve higher-order thinking in school education by infusing them in the curriculum without the need to include philosophy. This approach is hardly untried. To take the instance introduced earlier, in the ACARA model of critical and creative thinking, higher-order thinking is seen as a general competence to be developed throughout the curriculum without any reference to philosophy. Lipman's worry with attempts to embed or infuse higher-order thinking without philosophy is that they 'are bound to be fumbling, haphazard, and unavailing so long as students are not permitted to examine directly and for themselves the standards, criteria, concepts, and values that are needed to evaluate whatever it is that they are talking and thinking about' (Lipman 1991, p. 172). That is not the same as students applying standards, stating opinions, coming up with ideas, expressing their values, or engaging in discussion and debate. If higher-order thinking is to be developed across the years of schooling, it requires long-term and systematic acquisition of the tools of inquiry, exposure to the principles and practice of reasoning, and training in conceptual analysis. In short, it requires the capabilities that an extended exposure to philosophy will develop, but which are unlikely to 
receive the attention required if they are added to the demands placed on teachers in other areas of the curriculum without the support of philosophy.

Worries about an infusion model aside, there is still the possibility of introducing a non-disciplinary course specifically devoted to the development of higher-order thinking in place of philosophy. This sort of thing was widely advocated by the critical thinking movement. Lipman is right in commenting that, if the infusion approach tends to be superficial, the autonomous course in critical thinking is in danger of being irrelevant, unless it is supplemented by the former (Lipman 1991). This still leaves a combination of the two as a possible alternative; and so far as I can see, a sole reliance on the Generic Argument does not discount it. It is only in combination with relevant evidence or other claims that the argument becomes an effective counter to the idea of a non-disciplinary course in higher-order thinking. Candidate claims include: Lipman's methodological claim that 'higher-order thinking in the classroom rests largely on higher-quality dialogue ... a dialogue of styles of thought, of methods of analysis, of epistemological and metaphysical perspectives'; his criteriological contention that 'only philosophy can provide the logical and epistemological criteria that are now lacking in the curriculum'; and his assertion in regard to subject matter that 'philosophy provides ... a reservoir of fundamental humanistic ideas for classroom deliberation ... indispensable for secondary school ...' (Lipman 1991, pp. 69, 125 \& 179). Since the present discussion is concerned only with the strength of the Generic Argument, I will leave it to another time to inquire whether that argument provides a compelling case in favour of philosophy over non-disciplinary courses in higher-order thinking when presented in combination with one or more of these other claims.

Finally, I should say a brief word about evidence. It would require another investigation undertaken by a specialist in educational measurement to present a proper analysis of the relevant empirical studies in the literature. ${ }^{7}$ So I will restrict myself to making a couple of points in relation to what has already been said. In investigating this matter, it is worth looking at the growth of higher-order thinking abilities in studies of school populations where neither philosophy nor any other dedicated program has been taught. In regard to general reasoning, for example, there is cause to think that the abilities of secondary school students are often not

\footnotetext{
${ }^{7}$ A ready reference to the research has been produced by the Society for the Advancement of Philosophical Enquiry and Reflection in Education (SAPERE):

http://www.sapere.org.uk/Default.aspx?tabid=204. See also the list of research compiled by the Institute for the Advancement of Philosophy for Children (IAPC) at Montclair State University: http://www.montclair.edu/cehs/academics/centers-and-institutes/iapc/research/cognitive-skills/
} 
much greater than those of students in primary school, which themselves do not develop consistently throughout the primary years. Lipman himself makes this point in relation to studies carried out in New Jersey, adding that the mean score on the New Jersey Test of Reasoning was actually lower for community college freshmen than for students in Grades 4 to 8. (Lipman 1991, p. 28). This should not be altogether surprising, given that logic is not simply acquired along with language, automatically increasing with other aspects of linguistic development, and that schools do not pay systematic attention to the development of students' abilities to reason. I suspect that much the same is true of other aspects of higher-order thinking, even though it is now common for curriculum documents to make reference to them. The scattered efforts of teachers in various areas of the curriculum are unlikely to yield the desired results without the support of a dedicated course.

A survey of this kind would supply an appropriate background against which to view studies of special interventions designed to improve higher-order thinking. While such things as the differences between the performances of experimental and control groups in before-and-after test designs provide essential data in regard to targeted interventions, even small improvements in the short term are encouraging if the consequences of long-term non-intervention are as dismal as they appear to be. And in the long run, we need to see what difference long-term intervention makes against long-term non-intervention. After all, that really is the bigger picture when we come back to the starting point of putting thinking at the heart of school education.

As we saw earlier from a theoretical point of view, the Generic Argument needs to be bolstered by other claims regarding the educational benefits of philosophy vis-àvis non-disciplinary courses devoted to improvements in higher-order thinking. In practice, however, it may be that philosophy achieves better results than these other types of courses and this might be borne out by comparing the results achieved by the different types of intervention, either within a single study or by a broad survey of the literature. There would be a compelling case for the inclusion of philosophy along the lines discussed here if it can be shown to clearly outperform its competitors. This means that there is still much work to do. But then, who would pretend that it is an easy task to convince educational authorities that a dedicated space needs to be made for philosophy in an already overcrowded curriculum? 


\section{References}

Baron, JB \& Sternberg, RJ (eds) (1987) Teaching thinking skills: Theory and practice. WH Freeman \& Co, New York, NY.

Dewey, J (1910) How we think. DC Heath, Lexington, MA.

Dewey, J (1938) Logic: The theory of inquiry. Henry Holt and Company, New York, NY.

Dewey, J (1966) Democracy and education. Collier Macmillan, New York.

Dewey, J (1998) From absolutism to experimentalism. In LA Hickman \& TM Alexander (eds), The essential Dewey, Volume 1. Indiana University Press, Bloomington, IN, pp. 14-21.

Diggins, JP (1994) The promise of pragmatism. University of Chicago Press, Chicago, IL.

Lipman, M (1991) Thinking in education. Cambridge University Press, New York, NY.

McPeck, JE (1981) Critical thinking and education. Martin Robinson, Oxford.

Peirce, CS (1955) The fixation of belief. In J Buchler (ed), Philosophical writings of Peirce. Dover, New York, NY, pp. 5-22. 